\title{
Changes in Antioxidant Enzyme Activities and Lipid Peroxidation for Bentgrass Species in Response to Drought Stress
}

\author{
Michelle DaCosta ${ }^{1}$ and Bingru Huang ${ }^{2}$ \\ Department of Plant Biology and Pathology, Rutgers University, 59 Dudley Road, New Brunswick, \\ NJ 08901
}

\begin{abstract}
Additional Index words. Agrostis, turfgrass, superoxide dismutase, catalase, ascorbate peroxidase
Abstract. Previous investigations identified velvet bentgrass (Agrostis canina L.) as having higher drought resistance among bentgrass species. This study was designed to determine whether species variation in drought resistance for colonial bentgrass $(A$. capillaris $\mathrm{L}$.), creeping bentgrass $(A$. stolonifera $\mathrm{L}$.), and velvet bentgrass was associated with differences in antioxidant enzyme levels in response to drought. Plants of 'Tiger II' colonial bentgrass, 'L-93' creeping bentgrass, and 'Greenwich' velvet bentgrass were maintained in a growth chamber under two watering treatments: 1) well-watered control and 2) irrigation completely withheld for $28 \mathrm{~d}$ (drought stress). Prolonged drought stress caused oxidative damage in all three bentgrass species as exhibited by a general decline in antioxidant enzyme activities and an increase in lipid peroxidation. Compared among the three species, velvet bentgrass maintained antioxidant enzyme activities for a greater duration of drought treatment compared with both colonial bentgrass and creeping bentgrass. Higher antioxidant enzyme capacity for velvet bentgrass was associated with less lipid peroxidation and higher turf quality, leaf relative water content, and photochemical efficiency for a greater duration of stress compared with colonial bentgrass and creeping bentgrass. These results suggest that bentgrass resistance to drought stress could be associated with higher oxidative scavenging ability, especially for velvet bentgrass.
\end{abstract}

Plants under water deficit have a limited capacity for carbon fixation. Continued light absorption under drought stress may result in excessive energy that cannot be used for carbon fixation but may cause reduction of molecular oxygen, generating active oxygen species (AOS) such as singlet oxygen $\left({ }^{1} \mathrm{O}_{2}\right)$, superoxide $\left(\mathrm{O}_{2}^{--}\right)$, hydrogen peroxide $\left(\mathrm{H}_{2} \mathrm{O}_{2}\right)$, and hydroxyl radicals $(\mathrm{OH} \cdot)$ (Asada, 1999). These species can cause oxidative damage to lipids, nucleic acids, and proteins (Smirnoff, 1993). The production of AOS is not limited to drought stress and also occurs as a result of extremes in temperature (Mishra and Singhal, 1992; Schoner and Krause, 1990), high irradiance levels (Halliwell and Gutteridge, 1989a), disease (Apostol et al., 1989), and nutrient deficiency (Cakmak and Marschner, 1988).

Plants have developed an antioxidant defense system in response to the generation of AOS within plant tissues. The antioxidant defense system is comprised of enzymatic and nonenzymatic components that can be divided into two different types of repair mechanisms: 1) production of antioxidants or antioxidant enzymes that directly react with and scavenge AOS, including superoxide dismutase (SOD), catalase (CAT), ascorbate peroxidase (APX), peroxidase (POD), and $\alpha$ tocopherol; and 2) production of enzymes that regenerate oxidized antioxidants such as glutathione, glutathione reductase, ascorbate, and ascorbate reductase (Smirnoff, 1993). Accumulation of AOS results in increased antioxidant enzyme

Received for publication 12 Oct. 2006. Accepted for publication 15 Mar. 2007. Partial funding for this study was provided by the Rutgers University Center for Turfgrass Science.

We thank Emily Merewitz and Mahalaxmi Veerasamy for critical review and suggestions on the manuscript.

${ }^{1}$ Current address: Department of Plant, Soil, and Insect Sciences, University of Massachusetts, Amherst, MA 01003.

${ }^{2}$ Corresponding author. E-mail: huang@aesop.rutgers.edu. activities, providing indirect evidence for the extent of generation of AOS and the importance of these enzymes in scavenging free radicals (Smirnoff, 1993).

Drought stress resistance has been associated with either maintenance or increase in antioxidant enzyme activity levels in various plant species (Fu and Huang, 2001; Price and Hendry, 1989; Tanaka et al., 1990; Zhang and Schmidt, 1999). Antioxidant enzyme activity levels have been positively related to drought resistance in some species (Bowler et al., 1992; Jagtap and Bhargava, 1995; Lascano et al., 2001; Price and Hendry, 1989). Levels of SOD and CAT were maintained for a greater duration of combined drought and heat stress for a drought-tolerant cultivar of kentucky bluegrass (Poa pratensis L.) compared with a drought-susceptible cultivar (Wang and Huang, 2004). Zhang and Schmidt (1999) also found that kentucky bluegrass plants exhibiting higher levels of antioxidant enzyme activities maintained better turf quality under drought stress.

Under conditions of severe plant stress, the production of AOS may exceed the scavenging capacity of the antioxidant defense system (van Breusegem et al., 1998). As a consequence, AOS can accumulate and cause cellular damage such as lipid peroxidation or the oxidation of phospholipids and other unsaturated lipids. Peroxidation results in the breakdown of lipids and membrane function by causing loss of fluidity, lipid crosslinking, and inactivation of membrane enzymes (Girotti, 1990). The extent of lipid peroxidation can be calculated by measurement of malondialdehyde (MDA) content, which is a secondary breakdown product of lipid peroxidation (Halliwell and Gutteridge, 1989b). MDA content is a commonly used measurement for assessing lipid peroxidation and oxidative damage in both leaves and roots (Queiroz et al., 1998; Zhou and Zhao, 2004), and its maintenance of low levels has been associated with increased drought stress resistance in 
many plant species (Lima et al., 2002; Moran et al., 1994; Sairam et al., 1998; Zhang and Kirkham, 1994).

Identifying and understanding the function of antioxidant defense mechanisms are important for developing droughttolerant plants. Our previous studies have found that velvet bentgrass is more tolerant to drought stress than creeping bentgrass or colonial bentgrass as exhibited by higher turfgrass quality, leaf water content, and osmotic adjustment under drought stress (DaCosta and Huang, 2006a, 2006b). Whether bentgrass species variation in drought resistance is also associated with differences in antioxidant mechanisms is not well understood. The objectives of this study were to determine whether bentgrass species variation in drought resistance could be associated with differences in antioxidant enzyme levels in response to drought stress.

\section{Materials and Methods}

Plant materials and growth conditions. Sods of 'Tiger II' colonial bentgrass, 'L-93' creeping bentgrass, and 'Greenwich' velvet bentgrass were collected from 3-year-old field plots at the Rutgers Turfgrass Horticulture Farm II in North Brunswick, N.J. Each bentgrass cultivar was selected based on their superior performance in field trials in the northeastern United States. Plants were washed free of soil with water and transplanted into polyvinyl chloride (PVC) pots $(10 \mathrm{~cm}$ diameter, $40 \mathrm{~cm}$ high) filled with a sterilized mixture of 1 sand: 3 sandy loam soil (by volume) (fine-loamy, mixed, mesic, Typic Hapludult). A nylon screen covered the bottom of each PVC pot to contain the soil and allow for drainage of water from the pots.

Plants were grown in a greenhouse for $\approx 60 \mathrm{~d}$ to allow for establishment of the turf canopy and root systems and watered three times per week until water ran freely from the bottoms of the pots. All plants were hand clipped weekly at $\approx 3$ to $4 \mathrm{~cm}$ height and fertilized every $14 \mathrm{~d}$ with full-strength Hoagland's solution (Hoagland and Arnon, 1950) to provide nutrients and facilitate plant establishment before initiation of treatments. Plants were then transferred to a growth chamber set at 20/ $15^{\circ} \mathrm{C}$ day/night temperatures, $14 \mathrm{~h}$ of photoperiod, and photosynthetic photon flux density of $600 \mu \mathrm{mol} \cdot \mathrm{m}^{-2} \cdot \mathrm{s}^{-1}$ and allowed to acclimate for $14 \mathrm{~d}$ before treatments were imposed.

Treatments AND EXPERIMENTAL Design. The experiment consisted of two watering treatments: 1) well-watered control, irrigated three times per week to maintain soil moisture near pot capacity $[\approx 30 \%$ soil water content $(\mathrm{v} / \mathrm{v})$ as assessed by using the TRASE system (Soil Moisture Equipment, Santa Barbara, Calif.); and 2) drought stress, irrigation completely withheld. The treatments were arranged in a completely randomized design with a total of 24 experimental units. All treatments were replicated four times for each species and measurements were taken at multiple sampling dates during the treatment period. The treatments were ended after $28 \mathrm{~d}$, when the plants under drought treatment were desiccated and brown, which corresponded with soil moisture content of $\approx 6 \%(\mathrm{v} / \mathrm{v})$ (data not shown).

Measurements. Turf quality was rated visually based on turfgrass color (extent of chlorosis and leaf senescence), plant density, and degree of leaf wilting on a 1 -to- 9 scale $(1=$ brown, senesced, and desiccated turf; $9=$ fully turgid, green, and dense turf). A rating of 6 indicated the minimum acceptable turf quality based on these parameters (Morris, 2001).
Leaf relative water content (RWC) was determined weekly using 10 to 15 fully expanded leaves per pot according to Barrs and Weatherley (1962). Leaf samples were detached from the plants and immediately weighed to determine fresh weight (FW). Samples were placed into covered petri dishes filled with water for leaves to reach full hydration. After $\approx 18 \mathrm{~h}$ at $4{ }^{\circ} \mathrm{C}$, leaf samples were blotted dry and weighed immediately to determine turgid weight (TW). Leaf tissue was then dried in an oven at $75^{\circ} \mathrm{C}$ for $72 \mathrm{~h}$ to determine dry weight (DW). Leaf RWC was calculated as: $(\mathrm{FW}-\mathrm{DW}) /(\mathrm{TW}-\mathrm{DW}) \times 100$.

The ratio of variable fluorescence (Fv) to maximum fluorescence $(\mathrm{Fm})$, given as $\mathrm{Fv} / \mathrm{Fm}$, was measured to estimate percent photochemical efficiency of intact leaves. This measurement provides information on inhibition of electron transport from Photosystem II (PSII) and is thus useful for indicating changes in photosynthetic capacity attributable to stress. For further information on chlorophyll fluorescence, refer to Strasser et al. (2000). Fv/Fm was determined weekly using a fluorescence induction monitor (ADC BioScientific Ltd., Hoddesdon, UK). Before measurement, plants were dark-adapted for $30 \mathrm{~min}$ to obtain fully oxidized PSII centers. The chamber generating the fluorescence signals was placed on the plant canopy at three different locations per plant to obtain an average Fv/Fm value for each plant.

Sampling for antioxidant enzyme activities and lipid peroxidation was taken on the same days as RWC determination. Approximately $250 \mathrm{mg}$ of fresh leaf tissue was randomly sampled from each plant, frozen in liquid nitrogen, and stored at $-80{ }^{\circ} \mathrm{C}$ until further analysis. Extraction of SOD, CAT, APX, and MDA was performed as previously described by He et al. (2001) with modifications. Briefly, frozen leaves were homogenized with $4 \mathrm{~mL}$ of $150 \mathrm{~mm}$ ice-cold phosphate buffer $(\mathrm{pH} 7.0)$ with a mortar and pestle and centrifuged at 15,000 $g_{\mathrm{n}}$ for $20 \mathrm{~min}$ at $4{ }^{\circ} \mathrm{C}$. The supernatant was collected and used for determination of enzyme activity and MDA content.

APX activity was determined based on the oxidation of ascorbate using the method of Nakano and Assada (1981) with modifications. The reaction solution $(3 \mathrm{~mL})$ contained $100 \mathrm{~mm}$ sodium acetate buffer ( $\mathrm{pH} 5.8), 3 \mu \mathrm{M}$ ethylenediaminetetraacetic acid (EDTA), $5 \mathrm{mM} \mathrm{H}_{2} \mathrm{O}_{2}$, and $100 \mu \mathrm{L}$ of extracted solution. The reaction was initiated by adding the enzyme extract. Changes in absorbance at $290 \mathrm{~nm}$ were read every $10 \mathrm{~s}$ for $60 \mathrm{~s}$ using a spectrophotometer (Spectronic Genesys Series; Spectronic Instruments, Rochester, N.Y.). One unit of APX activity was defined as an absorbance change of 0.01 per min.

SOD activity was determined according to the method of Giannopolitis and Ries (1977) with modifications. The reaction solution (3 $\mathrm{mL}$ ) contained $50 \mathrm{~mm}$ phosphate buffer (pH 7.8), $60 \mu \mathrm{M}$ riboflavin (7,8-dimethyl-10-ribitylisoalloxazine), $195 \mathrm{~mm}$ methionine [2-amino-4-(methyl-thio)-butyric acid], $3 \mu \mathrm{M}$ EDTA, $1.125 \mathrm{~mm}$ nitro blue tetrazolium [NBT; 2,2' -di-p-nitrophenyl-5,5' -diphenyl-(3,3' -dimethoxy-4,4' diphenylene) ditetrazolium chloride], and $100 \mu \mathrm{L}$ of extracted solution. A solution containing no enzyme solution was used as the control. Test tubes were irradiated under fluorescent lights at $\approx 100 \mu \mathrm{mol} \cdot \mathrm{m}^{-2} \cdot \mathrm{s}^{-1}$ for $20 \mathrm{~min}$ and then transferred into the dark for $10 \mathrm{~min}$. The absorbance of each solution was measured at $560 \mathrm{~nm}$, and one unit of enzyme activity was defined as the amount of enzyme that would inhibit $50 \%$ of NBT photoreduction.

CAT activity was determined based on the oxidation of $\mathrm{H}_{2} \mathrm{O}_{2}$ using the method of Chance and Maehly (1955) with 
modifications. The reaction solution $(3 \mathrm{~mL})$ contained $50 \mathrm{~mm}$ phosphate buffer ( $\mathrm{pH} 7.0$ ), $45 \mathrm{~mm} \mathrm{H}_{2} \mathrm{O}_{2}$, and $100 \mu \mathrm{L}$ of extracted solution. The reaction was initiated by adding the enzyme solution. Changes in absorbance at $240 \mathrm{~nm}$ were read every $10 \mathrm{~s}$ for $60 \mathrm{~s}$ using a spectrophotometer. One unit of CAT activity was defined as the absorbance change of 0.01 per min.

MDA was determined according to the methods described by Heath and Packer (1968) and Dhindsa et al. (1981) with modifications. Briefly, $1 \mathrm{~mL}$ of extracted enzyme solution was added to $2 \mathrm{~mL}$ of a reaction solution containing $20 \%(\mathrm{v} / \mathrm{v})$ trichloroacetic acid and $0.5 \%(\mathrm{v} / \mathrm{v})$ thiobarbituric acid. The solution was placed in a water bath at $95{ }^{\circ} \mathrm{C}$ for $30 \mathrm{~min}$ and then transferred to an ice water bath. After the solution was centrifuged at $10,000 \mathrm{~g}_{\mathrm{n}}$ for $10 \mathrm{~min}$, the absorbance of the supernatant was read at 532 and $600 \mathrm{~nm}$. Nonspecific absorbance at $600 \mathrm{~nm}$ was subtracted from that at $532 \mathrm{~nm}$, and MDA content was calculated using this adjusted absorbance and the extinction coefficient of $155 \mathrm{~mm}^{-1} \cdot \mathrm{cm}^{-1}$ (Heath and Packer, 1968).

Statistical analysis. Effects of water treatment, species, and corresponding interactions were determined by analysis of variance according to the general linear model procedure of SAS (version 8.2; SAS Institute, Cary, N.C.). Analysis showed a significant interaction between grass species and watering treatment for the measured parameters. Therefore, differences between treatment means within a species were separated by Fisher's protected least significance difference (LSD) test at the $0.05 P$ level. For the comparison of species performance under drought stress, LSD values are provided in the figure legends.

\section{Results}

Turf quality (TQ) declined with drought duration for all three bentgrass species (Fig. 1). TQ for colonial bentgrass and creeping bentgrass declined to below that of well-watered controls at $14 \mathrm{~d}$ of drought treatment and declined to below minimal acceptable quality level (6.0) at $18 \mathrm{~d}$ of drought treatment. For velvet bentgrass, TQ fell to below the minimal acceptable quality level at $20 \mathrm{~d}$ of treatment. Velvet bentgrass maintained higher TQ compared with both colonial bentgrass and creeping bentgrass at 18,20 , and $25 \mathrm{~d}$ of drought treatment. By $28 \mathrm{~d}$ of drought treatment, TQ for all three species had declined to between 1.0 to 2.0, exhibiting severe leaf desiccation and leaf senescence.

Leaf RWC was maintained at $\approx 95 \%$ for all three species under well-watered conditions (Fig. 2). By $20 \mathrm{~d}$ of drought treatment, RWC declined to $36 \%, 46 \%$, and $78 \%$ for colonial bentgrass, creeping bentgrass, and velvet bentgrass, respectively. At the end of the drought treatment, RWC was $29 \%$, $38 \%$, and $48 \%$ for colonial bentgrass, creeping bentgrass, and velvet bentgrass, respectively. Velvet bentgrass maintained higher RWC compared with both colonial bentgrass and creeping bentgrass at 14,20 , and $28 \mathrm{~d}$ of drought treatment.

For the first $14 \mathrm{~d}$ of treatment, Fv/Fm of drought-treated plants remained at the same levels as that of well-watered control plants $(\approx 80 \%)$ for all three species (Fig. 3). By $20 \mathrm{~d}$ of drought treatment, $\mathrm{Fv} / \mathrm{Fm}$ declined to $52 \%, 55 \%$, and $67 \%$ for colonial bentgrass, creeping bentgrass, and velvet bentgrass, respectively. At the end of the drought treatment, $\mathrm{Fv} / \mathrm{Fm}$ levels declined to $36 \%, 36 \%$, and $44 \%$ for colonial bentgrass, creeping bentgrass, and velvet bentgrass, respectively. Velvet bentgrass
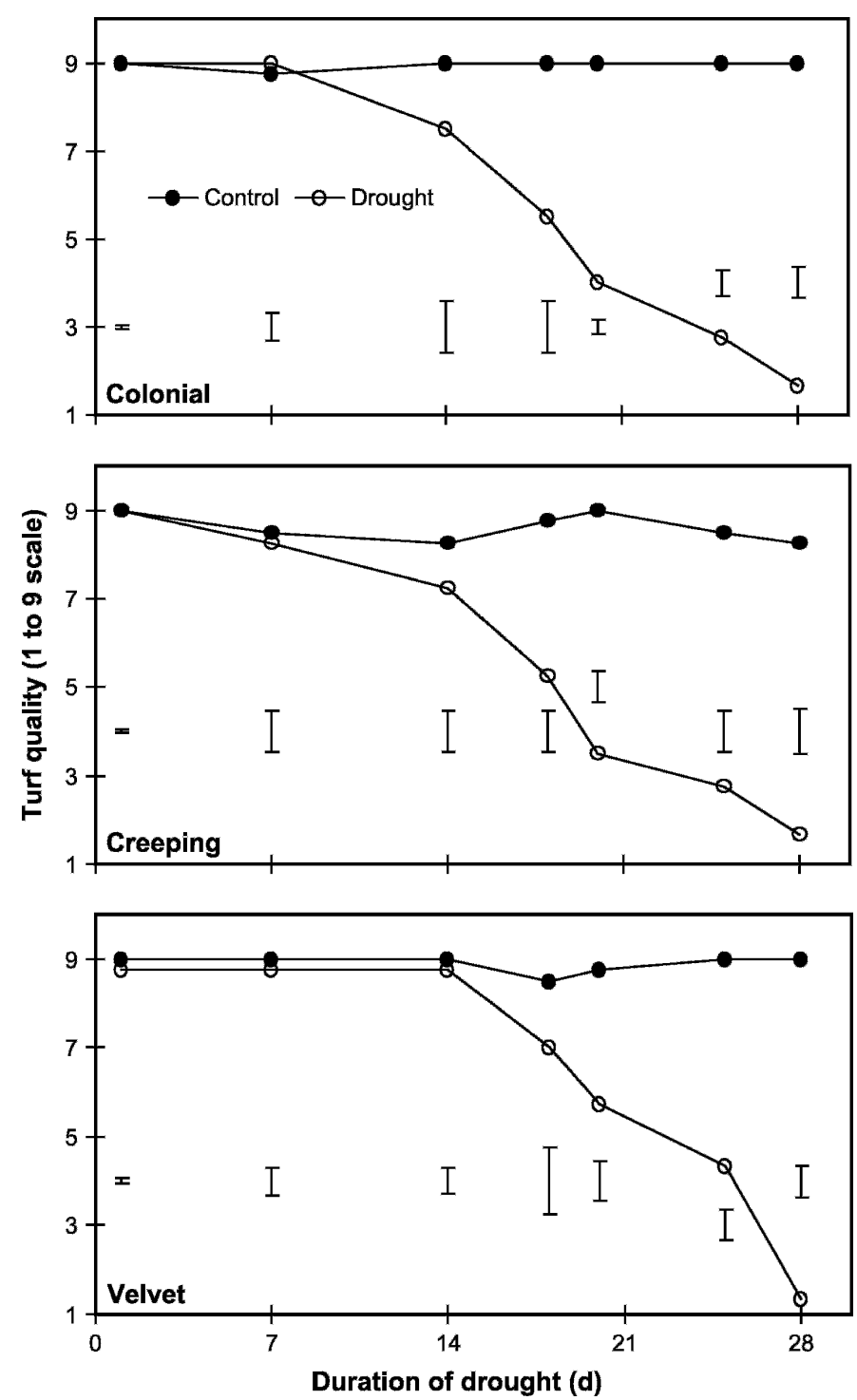

Fig. 1. Changes in TQ for colonial bentgrass, creeping bentgrass, and velvet bentgrass under well-watered (control) and drought treatments. A value of 9.0 represents the best quality (green, turgid, dense canopy) and 1.0 represents the lowest quality (brown, desiccated). Treatment means for each species are the average of four measurements (replicates). Vertical bars are LSD values ( $P \leq$ 0.05 ) for treatment comparisons at a given day of treatment. LSD values for species comparisons under drought stress were $0.5,0.6,1.1,1.4,0.7,0.9$, and 1.2 at 1, 7, 14, 18, 20, 25, and $28 \mathrm{~d}$ of drought treatment, respectively.

had higher $\mathrm{Fv} / \mathrm{Fm}$ compared with both colonial bentgrass and creeping bentgrass at $20 \mathrm{~d}$ of drought treatment, whereas no species differences were detected at other days of treatment.

Differences in leaf APX enzyme activities were not detected between well-watered and drought-stressed plants of colonial bentgrass and creeping bentgrass plants until $28 \mathrm{~d}$ of drought treatment when APX activity was $24 \%$ and $33 \%$ lower for drought-stressed plants of colonial bentgrass (55 units/g DW) and creeping bentgrass (58 units/g DW), respectively, compared with controls (Fig. 4). For velvet bentgrass, there were no differences in APX activity among treatments at 1 and $7 \mathrm{~d}$. APX activity increased by $15 \%$ compared with control plants at $14 \mathrm{~d}$ of drought stress, but by $28 \mathrm{~d}$ of treatment, APX activity was $20 \%$ lower for drought-stressed velvet bentgrass compared 

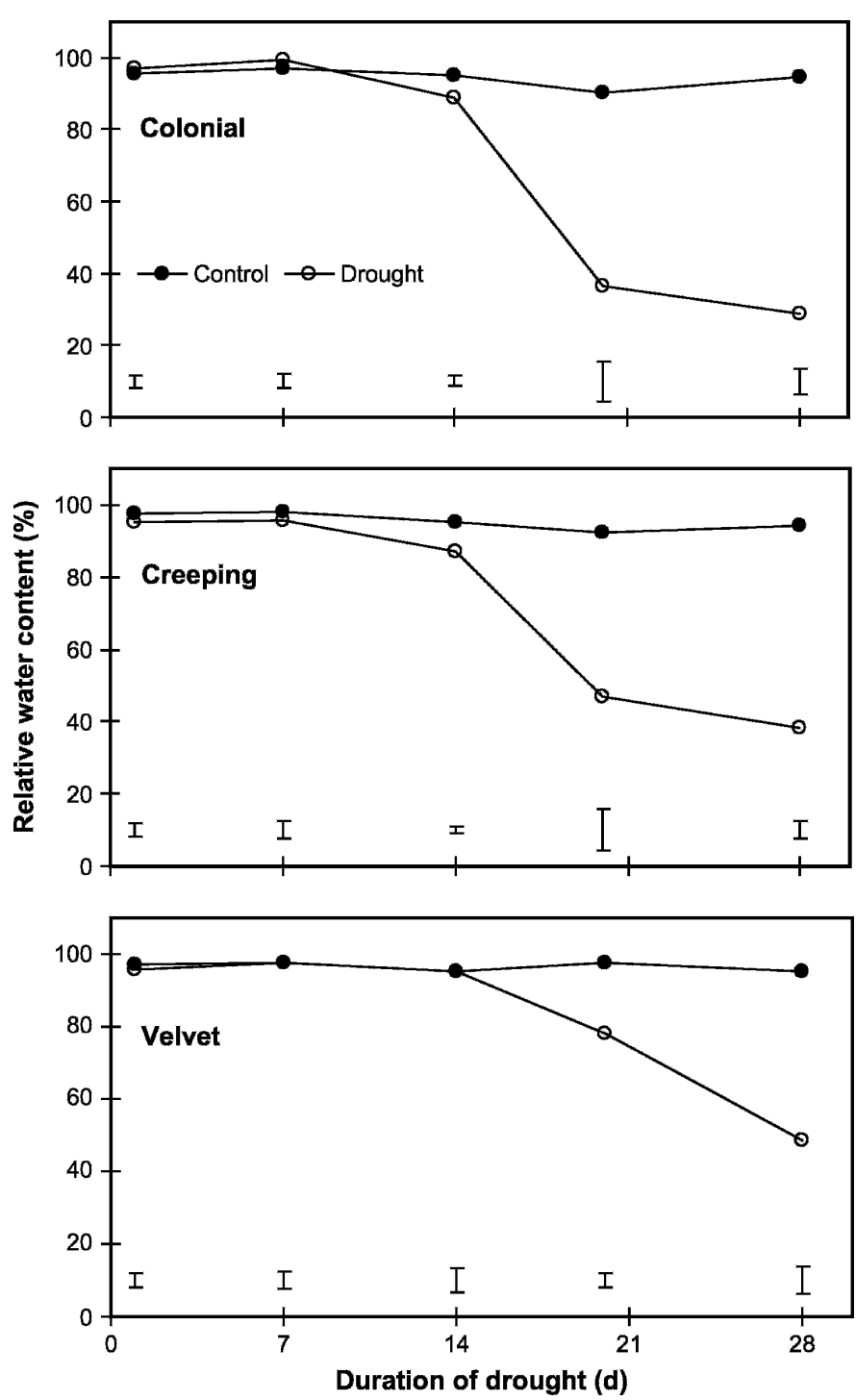

Fig. 2. Changes in leaf RWC for colonial bentgrass, creeping bentgrass, and velvet bentgrass under well-watered (control) and drought treatments. Treatment means for each species are the average of four measurements (replicates). Vertical bars are LSD values $(P \leq 0.05)$ for treatment comparisons at a given day of treatment. LSD values for species comparisons under drought stress were $3.6,4.8,5.9,12.0$, and 9.4 at 1, 7, 14, 20, and $28 \mathrm{~d}$ of drought treatment, respectively.

with well-watered controls. In general, velvet bentgrass exhibited $\approx 20 \%$ to $35 \%$ higher APX activity under well-watered and drought-stressed conditions compared with colonial bentgrass and creeping bentgrass.

Drought stress from 1 to $7 \mathrm{~d}$ had no effects on leaf SOD enzyme activities for any of the bentgrass species (Fig. 5). At $14 \mathrm{~d}$ of treatment, SOD activity of drought-stressed colonial bentgrass was $15 \%$ lower than respective control plants (1256 and 1070 units/g DW for drought-stressed and control, respectively); however, no differences in activity among treatments were detected for either creeping bentgrass or velvet bentgrass at this duration of drought treatment. SOD activity of drought-stressed plants was $47 \%, 39 \%$, and $30 \%$ lower at $20 \mathrm{~d}$ of treatment and $45 \%, 46 \%$, and $35 \%$ lower at $28 \mathrm{~d}$ of treatment compared with well-watered plants for colonial bentgrass, creeping bentgrass, and velvet bentgrass, respectively.
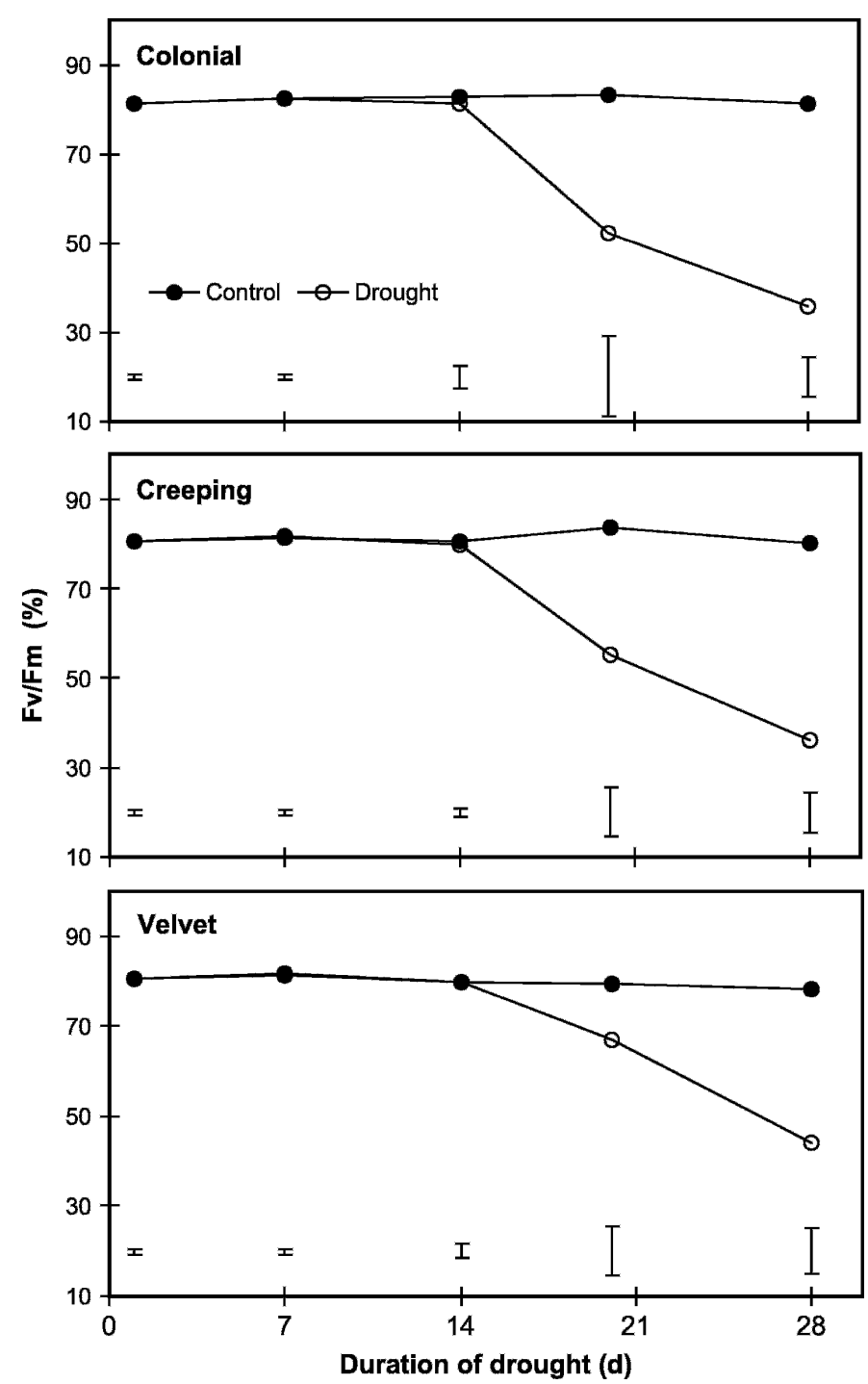

Fig. 3. Changes in photochemical efficiency (Fv/Fm) for colonial bentgrass, creeping bentgrass, and velvet bentgrass under well-watered (control) and drought treatments. Treatment means for each species are the average of four measurements (replicates). Vertical bars are LSD values $(P \leq 0.05)$ for treatment comparisons at a given day of treatment. LSD values for species comparisons under drought stress were $0.01,0.02,0.02,0.13$, and 0.09 at 1,7 , 14,20 , and $28 \mathrm{~d}$ of drought treatment, respectively.

No significant differences in leaf CAT enzyme activities were detected between well-watered and drought-stressed plants for all three bentgrass species at 1,7 , and $14 \mathrm{~d}$ of treatment (Fig. 6). CAT activity declined by $40 \%$ and $44 \%$ at $20 \mathrm{~d}$ of treatment for colonial bentgrass and creeping bentgrass, respectively, whereas no differences were detected for velvet bentgrass at this duration of drought treatment. By $28 \mathrm{~d}$ of drought treatment, CAT activity was $49 \%, 50 \%$, and $52 \%$ lower for drought-stressed colonial bentgrass, creeping bentgrass, and velvet bentgrass, respectively, compared with their respective well-watered controls. In general, velvet bentgrass exhibited $\approx 30 \%$ to $40 \%$ higher CAT activity under well-watered and drought-stressed conditions compared with colonial bentgrass and creeping bentgrass.

There were no statistically significant differences in leaf MDA content between well-watered and drought-stressed 

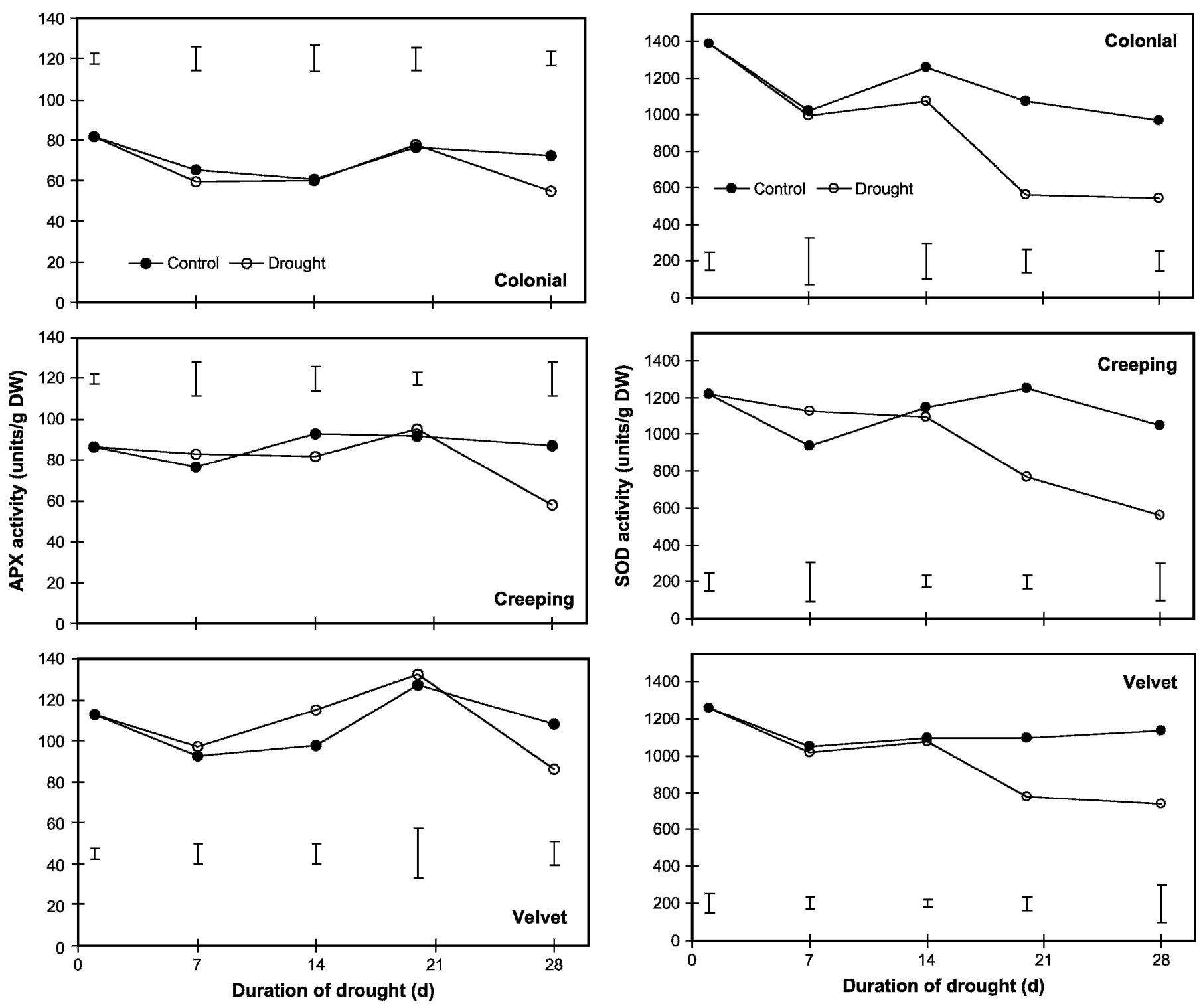

Fig. 4. APX enzyme activity for colonial bentgrass, creeping bentgrass, and velvet bentgrass under well-watered (control) and drought treatments. Treatment means for each species are the average of four measurements (replicates). Vertical bars are LSD values $(P \leq 0.05)$ for treatment comparisons at a given day of treatment. LSD values for species comparisons under drought stress were 12.4, $14.9,8.6,9.3$, and 10.1 at $1,7,14,20$, and $28 \mathrm{~d}$ of drought treatment, respectively.

plants at 1,7 , and $14 \mathrm{~d}$ of treatment for any of the bentgrass species (Fig. 7). MDA content was $40 \%$ and $20 \%$ higher for drought-stressed plants of colonial bentgrass and creeping bentgrass, respectively, compared with well-watered controls, whereas no differences in MDA content were detected among treatments for velvet bentgrass at this duration of drought treatment. By $28 \mathrm{~d}$ of drought treatment, MDA content was $83 \%, 85 \%$, and $62 \%$ greater in drought-stressed plants of colonial bentgrass, creeping bentgrass, and velvet bentgrass, respectively, compared with their respective well-watered controls.

\section{Discussion}

Our results demonstrated that drought stress resulted in significant declines in TQ, leaf RWC, and photochemical

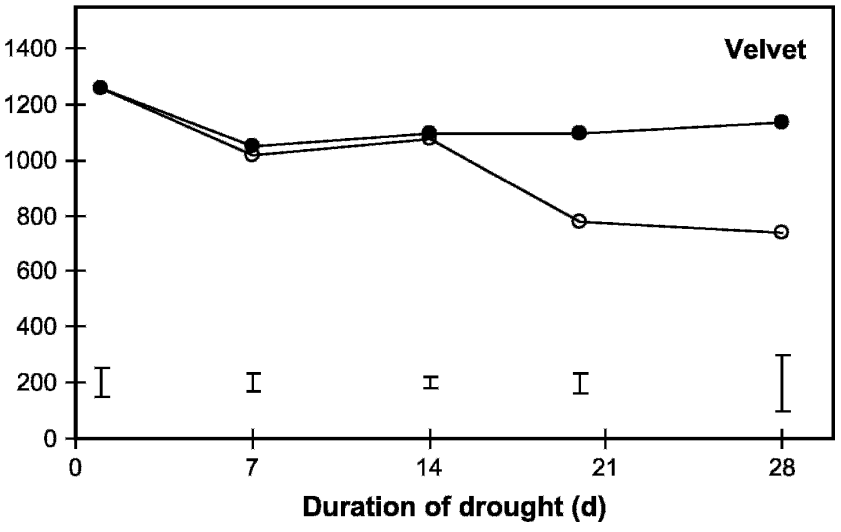

Fig. 5. SOD enzyme activity for colonial bentgrass, creeping bentgrass, and velvet bentgrass under well-watered (control) and drought treatments. Treatment means for each species are the average of four measurements (replicates). Vertical bars are LSD values $(P \leq 0.05)$ for treatment comparisons at a given day of treatment. LSD values for species comparisons under drought stress were $103.8,176.1,109.2,58.4$, and 171.5 at $1,7,14,20$, and $28 \mathrm{~d}$ of drought treatment, respectively.

efficiency $(\mathrm{Fv} / \mathrm{Fm})$ for all three bentgrass species, but to a lesser extent for velvet bentgrass compared with colonial bentgrass and creeping bentgrass. This suggested that velvet bentgrass was relatively less sensitive to drought stress compared with the other two bentgrass species. These findings were consistent with field studies in which velvet bentgrass exhibited higher TQ, leaf water status, and net photosynthetic rate under drought stress compared with creeping and colonial bentgrasses (DaCosta and Huang, 2006a, 2006b).

Decline in turf performance and physiological activities was accompanied by a general decrease in antioxidant enzyme activities and an increase in lipid peroxidation, indicating that scavenging ability within plant cells declined under prolonged drought stress for all three bentgrass species. Compared among the three species, velvet bentgrass exhibited a delayed decline 

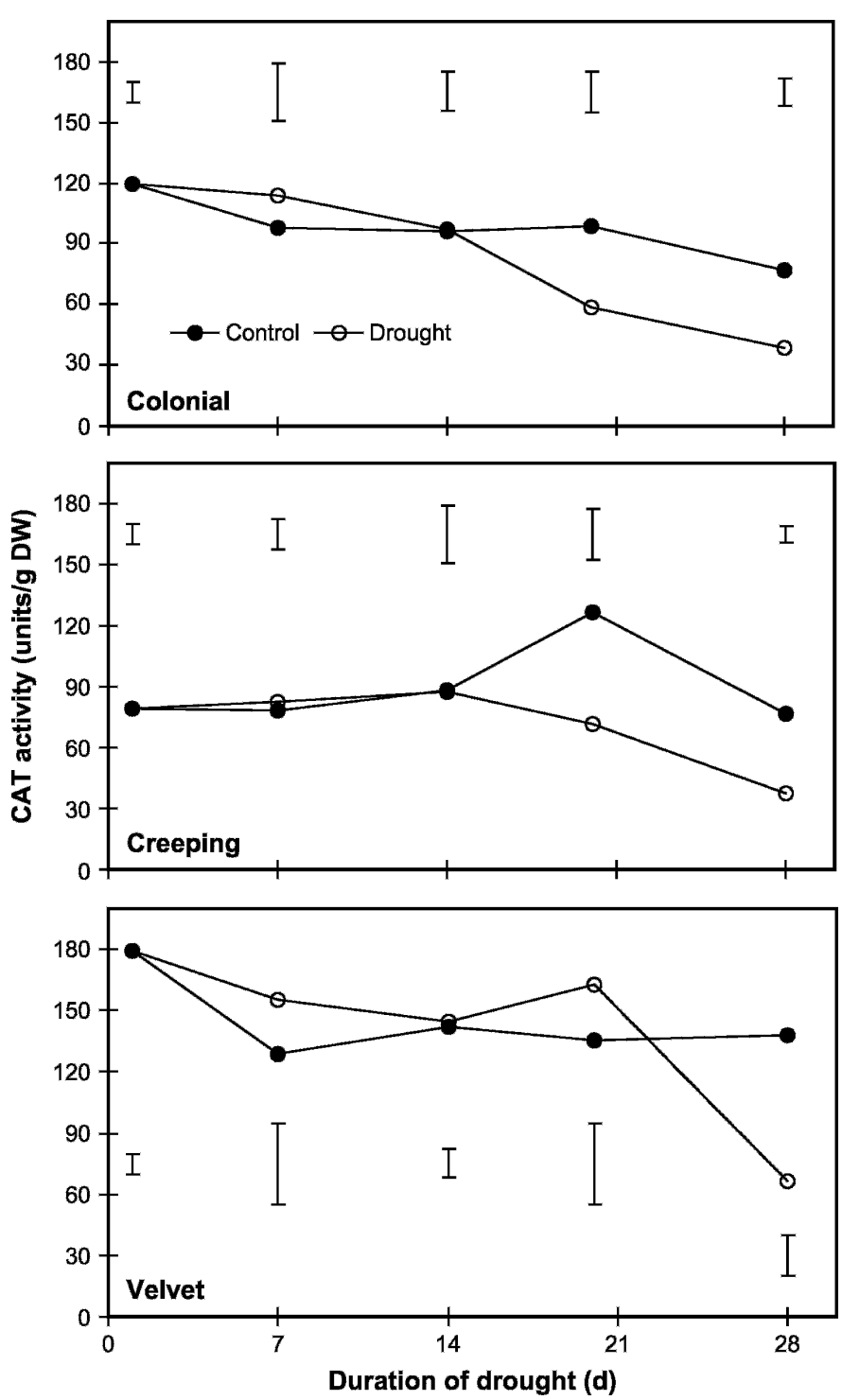

Fig. 6. CAT enzyme activity for colonial colonial bentgrass, creeping bentgrass, and velvet bentgrass under well-watered (control) and drought treatments. Treatment means for each species are the average of four measurements (replicates). Vertical bars are LSD values $(P \leq 0.05)$ for treatment comparisons at a given day of treatment. LSD values for species comparisons under drought stress were $20.4,25.2,18.5,26.5$, and 12.6 at 1, 7, 14, 20, and $28 \mathrm{~d}$ of drought treatment, respectively.

in antioxidant enzyme activities and less extensive lipid peroxidation compared with colonial bentgrass and creeping bentgrass. Furthermore, velvet bentgrass also exhibited $\approx 30 \%$ to $40 \%$ higher CAT activity and $20 \%$ to $35 \%$ higher APX activity under both well-watered and drought-stressed conditions compared with colonial bentgrass and creeping bentgrass. The delayed decline and higher activities of all three antioxidant enzymes for velvet bentgrass could explain the lower amount of lipid peroxidation and less severe membrane damage and thus higher TQ and photochemical efficiency compared with colonial bentgrass and creeping bentgrass. Greater resistance to drought stress has also previously been associated with either maintenance or an increase in antioxidant enzyme activity for a greater duration of stress compared with drought-susceptible plants in other plant species (Fu and
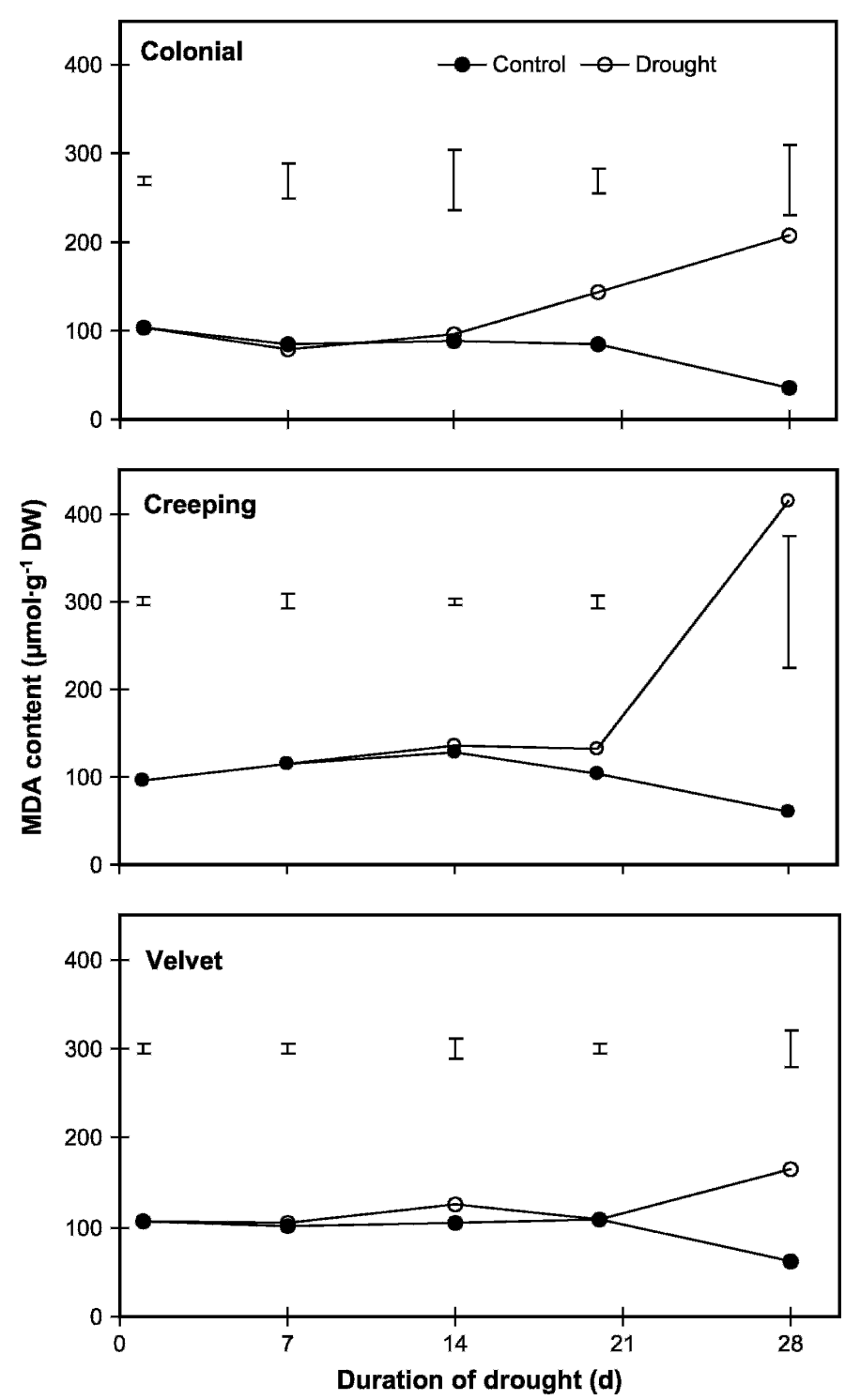

Fig. 7. Changes in the levels of lipid peroxidation, as measured using MDA content for colonial bentgrass, creeping bentgrass, and velvet bentgrass under well-watered (control) and drought treatments. Treatment means for each species are the average of four measurements (replicates). Vertical bars are LSD values $(P \leq 0.05)$ for treatment comparisons at a given day of treatment. LSD values for species comparisons under drought stress were 22.0, 19.5, 29.1, 19.2 , and 138.2 at $1,7,14,20$, and $28 \mathrm{~d}$ of drought treatment, respectively.

Huang, 2001; Price and Hendry, 1989; Tanaka et al., 1990; Zhang and Schmidt, 1999).

SOD catalyzes the dismutation of superoxide into $\mathrm{H}_{2} \mathrm{O}_{2}$ and $\mathrm{O}_{2}$ (Bowler et al., 1992) and is one of the most effective antioxidant enzymes in limiting oxidative damage (Asada, 1999). In turn, CAT and APX break down $\mathrm{H}_{2} \mathrm{O}_{2}$ into $\mathrm{H}_{2} \mathrm{O}$ and $\mathrm{O}_{2}$ (Bowler et al., 1992). SOD enzyme activity declined the earliest compared with either CAT or APX, particularly for colonial bentgrass that exhibited a $15 \%$ decrease in SOD activity by $14 \mathrm{~d}$ of drought treatment, when no differences were detected for creeping and velvet bentgrasses. In contrast, APX activity did not decline until $28 \mathrm{~d}$ of drought stress, when APX activity declined $\approx 20 \%$ to $30 \%$ below that of control levels for the three bentgrass species. This indicated that not all antioxidant enzymes change in their activities at the same 
time or with the same pattern in response to drought stress as has been observed in other investigations (Anderson et al., 1995; Saruyama and Tanida, 1995). The involvement of different antioxidant enzymes in AOS scavenging may vary with plant species and stress severity or duration. Fu and Huang (2001) reported that SOD and CAT activities of drought-stressed tall fescue (Festuca arundinacea Shreb.) and kentucky bluegrass were maintained at levels similar to well-watered plants for $\approx 20 \mathrm{~d}$ of drought treatment before declining below control levels; however, no significant changes in POD activity were observed between well-watered and drought-stressed plants of either species. Sairam et al. (2000) indicated that there were differences in the increase in activities of various antioxidants among tolerant genotypes of wheat (Triticum aestivum L.) such that one tolerant genotype had very high levels of ascorbic acid and APX, whereas another tolerant genotype exhibited higher SOD and CAT and intermediate ascorbic acid activities.

A major impact of environmental stress is cellular membrane modification, which may result in impaired function or total dysfunction of cells. Maintenance of membrane integrity represents a major mechanism of drought resistance in many plant species (Crowe et al., 1992). Increased levels of lipid peroxidation under prolonged drought stress, as indicated by MDA accumulation, occurred earlier and to a greater extent for colonial bentgrass and creeping bentgrass compared with velvet bentgrass. Greater membrane damage could be related to the impairment of antioxidant enzyme activities such as SOD and CAT, which also occurred earlier and to a greater extent for these two species. This suggested that colonial bentgrass and creeping bentgrass experienced earlier cell damage, indicating less drought resistance than velvet bentgrass. The maintenance of low levels of MDA accumulation has also been associated with better resistance to drought (Lima et al., 2002; Sairam et al., 1998; Zhang and Kirkham, 1994) and other environmental stresses (Luna et al., 2000; Sairam et al., 2000).

In summary, drought injury in bentgrass species was associated with oxidative stress as exhibited by a general decline in antioxidant enzyme activities and subsequent increases in lipid peroxidation. Velvet bentgrass was better adapted to drought stress as exhibited by higher TQ, leaf water relations, and leaf photochemical efficiency and lower levels of lipid peroxidation compared with both colonial bentgrass and creeping bentgrass under drought stress. The mechanisms by which plants avoid or tolerate drought stress are not mutually exclusive, and the same plant may use more than one strategy to adapt to periods of drought stress. Therefore, together with our previous research findings on physiological mechanisms contributing to variation in drought resistance among bentgrass species, we conclude that improved persistence of velvet bentgrass under drought stress is also associated with higher and prolonged maintenance of antioxidant enzyme activity.

\section{Literature Cited}

Anderson, M.D., T.K. Prasad, and C.R. Stewart. 1995. Changes in isozyme profiles of catalase, peroxidase, and glutathione reductase during acclimation to chilling in mesocotyls of maize seedlings. Plant Physiol. 109:1247-1257.

Apostol, I., P.F. Heinstein, and P.S. Low. 1989. Rapid stimulation of an oxidative burst during elicitation of cultured plant cells: Role in defense and signal transduction. Plant Physiol. 90:109-116.
Asada, K. 1999. The water-water cycle in chloroplasts: Scavenging of active oxygens and dissipation of excess photons. Annu. Rev. Plant Physiol. Plant Mol. Biol. 50:601-639.

Barrs, H.D. and P.E. Weatherley. 1962. A re-examination of the relative turgidity technique for estimating water deficit in leaves. Aust. J. Biol. Sci. 15:413-428.

Bowler, C., M.V. Montagu, and D. Inzé. 1992. Superoxide dismutase and stress tolerance. Annu. Rev. Plant Physiol. Plant Mol. Biol. 43:83-116.

Cakmak, I. and H. Marschner. 1988. Enhanced superoxide radical production in roots of zinc-deficient plants. J. Exp. Biol. 39:1449-1460.

Chance, B. and A.C. Maehly. 1955. Assay of catalase and peroxidase. Methods Enzymol. 2:764-775.

Crowe, J.H., F.A. Hoekstra, and L.M. Crowe. 1992. Anhydrobiosis. Annu. Rev. Physiol. 54:579-599.

DaCosta, M. and B. Huang. 2006a. Minimum water requirements for creeping, colonial, and velvet bentgrasses under fairway conditions. Crop Sci. 46:81-89.

DaCosta, M. and B. Huang. 2006b. Osmotic adjustment associated with variation in bentgrass tolerance to drought stress. J. Amer. Soc. Hort. Sci. 131:338-344.

Dhindsa, R.S., P.P. Dhindsa, and T.A. Thorpe. 1981. Leaf senescence: Correlation with increased levels of membrane permeability and lipid peroxidation, and decreased levels of superoxide dismutase and catalase. J. Exp. Bot. 32:93-101.

$\mathrm{Fu}$, J. and B. Huang. 2001. Involvement of antioxidants and lipid peroxidation in the adaptation of two cool-season grasses to localized drought stress. Environ. Exp. Bot. 45:105-114.

Giannopolitis, C.N. and S.K. Ries. 1977. Superoxide dismutase. I. Occurrence in higher plants. Plant Physiol. 59:309-314.

Girotti, A.W. 1990. Photodynamic lipid peroxidation in biological systems. Photochem. Photobiol. 51:497-509.

Halliwell, B. and J.M.C. Gutteridge. 1989a. Protection against oxidants in biological systems: The super oxide theory of oxygen toxicity, p. 86-123. In: B. Halliwell and J.M.C. Gutteridge (eds.). Free radicals in biology and medicine. Clarendon Press, Oxford, UK. Halliwell, B. and J.M.C. Gutteridge. 1989b. Lipid peroxidation: A radical chain reaction, p. 188-260. In: B. Halliwell and J.M.C. Gutteridge (eds.). Free radicals in biology and medicine. Clarendon Press, Oxford, UK.

He, Y., Y. Liu, Q. Chen, A. Bian, and W. Chen. 2001. Comparison of the optimal $\mathrm{pH}$ for 4 antioxidant enzymes in the seedlings of tall fescue (Festuca arundinacea Schreb.) and kentucky bluegrass (Poa pratensis L.). J. Nanjing Agr. Univ. 24:1-4.

Heath, R.L. and L. Packer. 1968. Photoperoxidation in isolated chloroplasts. Arch. Biochem. Biophys. 125:189-198.

Hoagland, D.R. and D.I. Arnon. 1950. The water-culture method for growing plants without soil, p. 31. California Agr. Expt. Sta. Circ. 347. College of Agriculture University of California, Berkeley.

Jagtap, V. and S. Bhargava. 1995. Variation in the antioxidant metabolism of drought tolerant and drought susceptible varieties of Sorghum bicolor (L.) Moench. exposed to high light, low water and high temperature stress. J. Plant Physiol. 145:195-197.

Lascano, H.R., G.E. Antonicelli, C.M. Luna, M.N. Melchiorre, L.D. Gomez, R.W. Racca, V.S. Trippi, and L.M. Casano. 2001. Antioxidant system response of different wheat cultivars under drought: Field and in vitro studies. Austral. J. Agr. Res. 28:1095-1102.

Lima, A.L.S., F.M. DaMatta, H.A. Pinheiro, M.R. Totola, and M.E. Loureiro. 2002. Photochemical responses and oxidative stress in two clones of Coffea canephora under water deficit conditions. Environ. Exp. Bot. 47:239-247.

Luna, C., L.G. Seffino, C. Arias, and E. Taleisnik. 2000. Oxidative stress indicators as selection tools for salt tolerance in Chloris gayana. Plant Breed. 119:341-345.

Mishra, R.K. and G.S. Singhal. 1992. Function of photosynthesis apparatus of intact wheat leaves under high light and heat stress and its relationship with peroxidation of thylakoid lipids. Plant Physiol. 98:1-6. 
Moran, J.F., M. Becana, I. Iturbe-Ormaetxe, S. Frechilla, R.V. Klucas, and P. Aparicio-Tejo. 1994. Drought induces oxidative stress in pea plants. Planta 194:346-352.

Morris, K.N. 2001. A guide to NTEP turfgrass ratings. 4 Dec. 2006. $<$ http://www.ntep.org/reports/ratings.htm>.

Nakano, Y. and K. Assada. 1981. Hydrogen peroxide is scavenged by ascorbate specific peroxidase in spinach chloroplasts. Plant Cell Physiol. 22:867-880.

Price, A.H. and G.A.F. Hendry. 1989. Stress and the role of activated oxygen scavengers and protective enzymes in plants subjected to drought. Biochem. Soc. Trans. 17:493-494.

Queiroz, C.G.S., A. Alonso, M. Mares-Guia, and A.C. Magalhaes. 1998. Chilling-induced changes in membrane fluidity and antioxidant enzyme activities in Coffea arabica L. roots. Biol. Plant. 41:403-413.

Sairam, R.K., P.S. Deshmukh, and D.C. Saxena. 1998. Role of antioxidant systems in wheat gentoypes tolerance to water stress. Biol. Plant. 41:387-394.

Sairam, R.K., G.C. Srivastava, and D.C. Saxena. 2000. Increased antioxidant activity under elevated temperatures: A mechanism of heat stress tolerance in wheat genotypes. Biol. Plant. 43:245-251.

Saruyama, H. and M. Tanida. 1995. Effect of chilling on activated oxygen-scavenging enzymes in low temperature-sensitive and tolerant cultivars of rice (Oryza sativa L.). Plant Sci. 109:105-113.

Schoner, S. and G.H. Krause. 1990. Protective systems against active oxygen species in spinach: Response to cold acclimation in excess light. Planta 180:383-389.
Smirnoff, N. 1993. The role of active oxygen in the response of plants to water deficit and desiccation. New Phytol. 125:27-58.

Strasser, R.J., A. Srivastava, and M. Tsimilli-Michael. 2000. The fluorescence transient as a tool to characterize and screen photosynthetic samples, p. 445-483. In: M. Yunus, U. Pathre, and P. Mohanty (eds.). Probing photosynthesis: Mechanisms, regulation and adaptation. Taylor and Francis, London.

Tanaka, K., R. Masuda, T. Sugimato, K. Omasa, and T. Sakasi. 1990. Water deficiency-induced changes in the contents of defensive substances against active oxygen in spinach leaves. Agr. Biol. Chem. 54:2629-2634.

van Breusegem, F., M. van Montagu, and D. Inze. 1998. Engineering stress tolerance in maize. Outlook Agr. 27:115-124.

Wang, Z. and B. Huang. 2004. Physiological recovery of kentucky bluegrass from simultaneous drought and heat stress. Crop Sci. 44:1729-1736.

Zhang, J. and M.B. Kirkham. 1994. Drought-stress-induced changes in activities of superoxide dismutase, catalase, and peroxidase in wheat species. Plant Cell Physiol. 35:785-791.

Zhang, X. and R.E. Schmidt. 1999. Antioxidant response to hormonecontaining product in kentucky bluegrass subjected to drought. Crop Sci. 39:545-551.

Zhou, R. and H. Zhao. 2004. Seasonal pattern of antioxidant enzyme system in the roots of perennial forage grasses grown in alpine habitat, related to freezing tolerance. Physiol. Plant. 121: 399-408. 